\title{
Inductively Coupled Plasma-Induced Etch Damage of GaN p-n Junctions
}

R. J. Shul, L. Zhang, A. G. Baca, C. G. Willison, and J. Han

Sandia National Laboratories, Albuquerque, NM 87185

S. J. Pearton and F. Ren

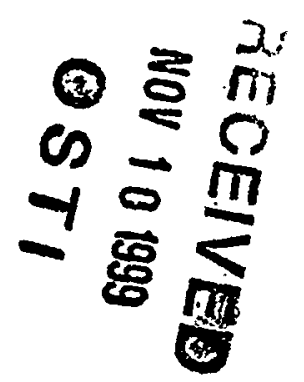

Department of Materials Science and Engineering, University of Florida, Gainesville, FL 32611

\begin{abstract}
Plasma-induced etch damage can degrade the electrical and optical performance of III-V nitride electronic and photonic devices. We have investigated the etch-induced damage of an Inductively Coupled Plasma (ICP) etch system on the electrical performance of mesa-isolated GaN pn-junction diodes. GaN p-i-n mesa diodes were formed by $\mathrm{Cl}_{2} / \mathrm{BCl}_{3} / \mathrm{Ar} \mathrm{ICP}$ etching under different plasma conditions. The reverse leakage current in the mesa diodes showed a strong relationship to chamber pressure, ion energy, and plasma flux. Plasma induced damage was minimized at moderate flux conditions $(\leq 500 \mathrm{~W})$, pressures $\geq 2 \mathrm{mTorr}$, and at ion energies below approximately $-275 \mathrm{~V}$.
\end{abstract}




\section{INTRODUCTION}

The fabrication of a wide variety of GaN-based photonic and electronic devices depends i on dry etching either partially or completely through a pn-junction. Examples of these devices 3.

inciude laser diodes (LDs), ${ }^{(1)}$ light-emitting diodes (LEDs), ${ }^{(2)}$ heterojunction bipolar transistors (

$(\mathrm{HBTs}){ }^{(3-5)} \mathrm{p}-\mathrm{i}-\mathrm{n}$ photodiodes, ${ }^{(6-8)}$ and junction field effect transistors (JFETs) ${ }^{(9)}$ With the $\because$

exception of the low energy electron enhanced etching (LE4) process, ${ }^{(10-12)}$ all dry etching methods rely on ion-assisted removal of the substrate material. ${ }^{(13)}$ Due to the relatively high bond energy ( $8.92 \mathrm{eV} /$ atom) of GaN, the threshold ion energy for the onset of dry etching is typically on the order of $25 \mathrm{eV}$. Under conditions of both high ion flux $\left(\sim 10^{17} \mathrm{ions} / \mathrm{cm}^{2} \mathrm{sec}\right)$ and ion energies above this threshold, etch rates $>5,000 \mathrm{~A} / \mathrm{min}$ are readily achieved for $\mathrm{GaN}$ in Inductively Coupled Plasma (ICP) or Electron Cyclotron Resonance (ECR) etch systems. ${ }^{(13.15)}$ Under the lower flux conditions $\left(\sim 10^{15}\right.$ ions/ $\left./ \mathrm{cm}^{2} \mathrm{sec}\right)$ typical of reactive ion etching (RIE), the resultant etch rates are generally much slower $(<1,000 \mathrm{~A} / \mathrm{min}) .{ }^{(16 .} .{ }^{17)} \quad$ Unfortunately, under conditions of high plasma flux and energetic ion bombardment plasma-induced damage often occurs. Plasma-induced damage can take many forms, several of which are summarized below. ${ }^{(18-20)}$

a) Energetic ion bombardment can create lattice defects or dislocations, formation of dangling bonds on the surface, or implanted etch ions. These defects often act as deep level states and produce compensation, trapping, or recombination in the material. Damage as deep as $1000 \mathrm{~A}$ has been reported in GaAs. ${ }^{(18)}$

b) Hydrogen is often present during the etch process due to either its use in the plasma chemistry, residual water vapor in the chamber, or erosion of the photoresist mask, and can unintentionally passivate the dopants present in the material up to depths of several thousand angstroms. 


\section{DISCLAIMER}

This report was prepared as an account of work sponsored by an agency of the United States Government. Neither the United States Government nor any agency thereof, nor any of their employees, make any warranty, express or implied, or assumes any legal liability or responsibility for the accuracy, completeness, or usefulness of any information, apparatus, product, or process disclosed, or represents that its use would not infringe privately owned rights. Reference herein to any specific commercial product, process, or service by trade name, trademark, manufacturer, or otherwise does not necessarily constitute or imply its endorsement, recommendation, or favoring by the United States Government or any agency thereof. The views and opinions of authors expressed herein do not necessarily state or reflect those of the United States Government or any agency thereof. 


\section{DISCLAIMER}

Portions of this document may be illegible in electronic image products. Images are produced from the best available original document. 
c) Polymer deposition may occur during the use of plasma chemistries containing $\mathrm{CH}_{x}$ radicals or reactions of the photoresist masks with the plasma.

d) Non-stoichiometric surfaces may be formed due to preferential loss of one of the lattice constituents. This is often attributed to either preferential sputter desorption of the lighter element in the film or large differences in the volatility of the respective etch products. Nonstoichiometric depths are typically $<100 \mathrm{~A}$.

Low damage etching can be achieved by either increasing the chemical activity of the etch process or decreasing the ion energy, however this can decrease the etch rate or anisotropy and minimize the utility of the etch. Therefore, etch processes must address several issues including sidewall profile control, etch rates, surface morphology, and low-damage for optimum device performance. Since $\mathrm{GaN}$ is more chemically inert than GaAs and has higher bonding energies, it may be reasonable to use higher ion energies or plasma flux during the etch process with potentially less damage to the material. Most of the damage studies on the group-III nitrides have focused on Schottky diodes; where, in virtually all cases, significant degradation in reverse breakdown voltage and barrier height was reported due to creation of a near-surface, $n$ type conducting layer in the GaN. ${ }^{(21-24)}$ Plasma-induced sidewall damage has only been reported for GaAs and InP mesa isolated diodes where metallurgical junctions were exposed at the perimeter. ${ }^{(25-28)}$ These devices are especially sensitive to sidewall damage if the perimeter-to-area ratios are large. Sidewall damage can affect both forward- and reverse-bias currents. Plasmainduced damage may cause an increase of mid-bandgap states and surface channel conduction, which in turn increases the reverse-bias-leakage current of the pn-junction.

In this paper we report ICP etch-induced sidewall damage effects on reverse-bias leakage currents of $\mathrm{GaN}$ pn-junction diodes. Reverse-bias leakage currents, mesa sidewall profiles, etch rates, and sidewall and surface morphologies are reported. 


\section{EXPERIMENTAL}

Layer structures were grown by Metal Organic Chemical Vapor Deposition on c-plane $\mathrm{Al}_{2} \mathrm{O}_{3}$ substrates at $1040^{\circ} \mathrm{C}{ }^{(29)}$ The structure consisted of a low temperature $\left(530^{\circ} \mathrm{C}\right) \mathrm{GaN}$ buffer, $1.0 \mu \mathrm{m}$ of $\mathrm{n}\left(2 \times 10^{17} \mathrm{~cm}^{-3}\right.$, Si-doped) $\mathrm{GaN}, 0.2 \mu \mathrm{m}$ of nominally undoped $\left(\mathrm{n} \sim 10^{16} \mathrm{~cm}^{-3}\right) \mathrm{GaN}$ and $1.0 \mu \mathrm{m}$ of $\mathrm{p}\left(\mathrm{N}_{\mathrm{A}} \sim 5 \times 10^{19} \mathrm{~cm}^{-3}, \mathrm{Mg}\right.$-doped) GaN. The p-ohmic metal (Ni/Au) was deposited by ebeam evaporation and lift-off, then alloyed at $750^{\circ} \mathrm{C}$. A mesa was then formed by $\mathrm{BCl}_{3} / \mathrm{Cl}_{2} / \mathrm{Ar}$ (8/32/5 sccm) ICP etching to a depth of $1.6 \mu \mathrm{m}$ under different plasma conditions in order to examine the effect of ion energy and plasma flux. The ICP reactor was a load-locked PlasmaTherm SLR 770, which used a $2 \mathrm{MHz}, 3$ turn coil ICP source. All samples were mounted using a thermally conductive paste on an anodized $\mathrm{Al}$ carrier that was clamped to the cathode and cooled with He gas. The ion energy or dc-bias was defined by superimposing a rf-bias (13.56 $\mathrm{MHz}$ ) on the sample. The n-type ohmic metallization (Ti/Al) was then deposited and patterned by lift-off, to produce the structure shown in Figure 1. Reverse I-V measurements were made on $300 \mu \mathrm{m}$ diameter diodes with a HP 4145B semiconductor parameter analyzer. In this study the reverse leakage current was measured at a bias of $-30 \mathrm{~V}$ unless otherwise mentioned. Etch rates were calculated from bulk GaN samples patterned with $\mathrm{AZ}-4330$ photoresist. The depth of etched features was measured with an Alpha-Step profilometer after the photoresist was removed. Etch profile and surface morphology were analyzed with scanning electron microscopy (SEM) and atomic force microscopy (AFM), respectively.

\section{RESULTS AND DISCUSSION}

Figure 2 shows the effect of dc-bias on the reverse junction leakage current, along with the corresponding GaN etch rates. There is little effect on the reverse current below dc-biases of 
$-250 \mathrm{~V}$. This corresponds to an ion energy of approximately $-275 \mathrm{eV}$, since this energy is the sum of dc-bias and plasma potential (about $-25 \mathrm{eV}$ in this tool under these conditions). The reverse current decreases slightly as the dc-bias is increased from -25 to $-50 \mathrm{~V}$. This may result from the sharp increase in etch rate which leads to faster removal of near-surface damage. The reverse leakage current increased rapidly above $-275 \mathrm{~V}$ dc-bias, which is a clear indication of severe damage accumulation in the sidewall. The damage probably takes the form of point defects such as nitrogen vacancies which increases the n-type conductivity of the surface. The total reverse current density, $\mathrm{J}_{\mathrm{R}}$ is the sum of three components, namely diffusion, generation and surface leakage according to ${ }^{(30)}$

$$
J_{R}=\left(\frac{e D_{h}}{l_{h} N_{D}}+\frac{e D_{e}}{l_{e} N_{A}}\right) n_{i}{ }^{2}+\frac{e W n_{i}}{\tau_{g}}+J_{S L}
$$

where $\mathrm{e}$ is the electronic charge, $D_{\mathfrak{e}^{\prime h}}$ are the diffusion coefficients of electrons or holes, $l_{\mathrm{e}_{\mathrm{h}}}$ are the lengths of the $n$ and $p$ regions outside the depletion region in a.p- $n$ junction, $N_{D . A}$ are the donor/acceptor concentrations on either side of the junction, $n_{i}$ is the intrinsic carrier concentration, $\mathrm{W}$ the depletion width, $\tau_{\mathrm{g}}$ the thermal generation lifetime of carriers and $\mathrm{J}_{\mathrm{SL}}$ is the surface current component which is bias-dependent. The latter component is most affected by the dry etch process, and dominates the reverse leakage in diodes etched at high ion energies.

GaN sidewall profiles and etch morphologies have been evaluated from previous results as a function of dc-bias and are shown in Figure 3. The etch became more anisotropic as the dcbias increased from (a) -50 to (b) $-150 \mathrm{~V}$ dc-bias due to the perpendicular nature of the ion bombardment energies. However, at (c) $-300 \mathrm{~V}$ dc-bias a tiered etch profile with vertical striations in the sidewall was observed due to erosion of the mask-edge under high ion bombardment energies. The physical degradation (both profile and morphology) of the etched sidewall at $-300 \mathrm{~V}$ could help explain higher reverse leakage currents above $-250 \mathrm{~V}$ dc-bias. 
Under high bias conditions, more energetic ions scattering from the surface could strike the sidewalls with significant momentum thus increasing the likelihood of increased damage and higher reverse leakage currents. In addition, the sidewall roughness also results in a larger effective perimeter of the diode mesa causing higher reverse leakage currents. Under low bias conditions, the sidewall profile is less anisotropic implying increased lateral etching of the $\mathrm{GaN}$ (undercutting of the mask). Under these conditions the etch process becomes dominated by the chemical component of the etch mechanism, which may account for the slightly higher reverse leakage observed at $-25 \mathrm{~V}$ dc-bias.

Figure 4 shows the effect of ICP source power on the junction reverse leakage current. The plasma flux is proportional to source power. In this experiment the ion energy was held constant at $-100 \mathrm{~V}$ dc-bias. There is minimal effect on leakage current for source powers $\leq 500$ $\mathrm{W}$, with severe degradation of the junction characteristics at higher powers even though the $\mathrm{GaN}$ etch rate continues to increase. This finding shows that the conditions that produce the highest etch rate are not necessarily those that lead to the least damage. Increased sidewall damage under high plasma flux conditions may be due to increased ion scattering as well as more interactions of reactive neutrals with the sidewall of the mesa. SEM micrographs (Figure 5) from bulk GaN samples also show a degradation of sidewall profile under high ICP source power conditions. In Figure 5c, at an ICP source power of 1000W, the sidewall has an undercut profile implying lateral etching and a strong chemical component of the etch with vertical striations possibly due to erosion of the mask edge. However, sidewall profiles at $250 \mathrm{~W}$ (Figure 5a) and $500 \mathrm{~W}$ (Figure 5b) are quite anisotropic and smooth.

Reverse leakage currents were relatively insensitive to chemistry effects in a $\mathrm{Cl}_{2} / \mathrm{BCl}_{3} / \mathrm{Ar}$ ICP discharge. As shown in Figure 6, the reverse leakage current ranged between $\sim 10$ and $40 \mathrm{nA}$ as the $\% \mathrm{Cl}_{2}$ changed from 0 to 100 . For these experiments, a second $\mathrm{GaN}$ wafer was used which 
had a much rougher surface morphology and may account for higher reverse leakage currents measured under standard conditions ( $32 \mathrm{sccm} \mathrm{Cl}_{2}, 8 \mathrm{sccm} \mathrm{BCl} \mathrm{s}_{3}, 5 \mathrm{sccm} \mathrm{Ar}, 500 \mathrm{~W}$ ICP source power, $-250 \mathrm{~V}$ dc-bias, and $2 \mathrm{~m}$ Torr pressure). The fact that the $\mathrm{Cl}_{2}$ percentage in the plasma has little effect on the reverse leakage current emphasizes that the physical component of the etching is mainly responsible for the near-surface damage, since optical emission spectroscopy has shown that the atomic chlorine density in the plasma is a strong function of the $\mathrm{Cl}_{2}: \mathrm{BCl}_{3}$ ratio in our system. These atomic chlorine neutrals are the dominant reactive species responsible for the etching, but require additional ion bombardment to break bonds in the GaN and assist in etch product desorption. The $\mathrm{GaN}$ etch rate increased as $\mathrm{Cl}_{2}$ was added to the $\mathrm{BCl}_{3} / \mathrm{Ar}$ plasma up to 80\%. In a $\mathrm{Cl}_{2} / \mathrm{Ar}$ plasma the $\mathrm{GaN}$ etch rate decreased due to lower concentrations of reactive $\mathrm{Cl}$ neutrals. ${ }^{(31)}$ Etch profiles were relatively anisotropic and smooth except for the $\mathrm{Cl}_{2} / \mathrm{Ar}$ plasma where the etch was slightly rougher.

In Figure 7, reverse leakage currents and $\mathrm{GaN}$ etch rates are plotted as a function of chamber pressure. Under low pressure conditions (1 mTorr) the reverse leakage was high possibly due to higher mean free paths and more energetic collisions of the plasma ions with the sidewall. As the pressure was increased to $2 \mathrm{mTorr}$ and higher, the reverse leakage currents decreased and remained relatively constant. The $\mathrm{GaN}$ etch rate increased for pressures up to 5 mTorr and then decreased at $10 \mathrm{mTorr}$. Lower reverse leakage currents at higher pressures may be attributed to lower plasma densities, redeposition, or polymer formation on the substrate surface. Under low pressure etch conditions the etch was anisotropic and smooth, however at 10 mTorr the etch profile was undercut and poorly defined due to a lower mean-free path, higher collisional scattering of the ions, and increased lateral etching of the GaN. For the most part, the rms surface roughness was $<2 \mathrm{~nm}$ independent of pressure, similar to the rms roughness for the 
as-grown $\mathrm{GaN}$. This is expected since the ion energy is below the value where surface roughening typically occurs. ${ }^{(13.14)}$

Two samples were annealed in this study to determine if the defects caused by plasmainduced-damage to the $\mathrm{p}-\mathrm{n}$ junction could be removed and low reverse leakage currents recovered. The first sample was initially exposed to the following ICP conditions: $32 \mathrm{sccm} \mathrm{Cl}_{2}$, $8 \mathrm{sccm} \mathrm{BCl}{ }_{3}, 5 \mathrm{sccm} \mathrm{Ar,} 500 \mathrm{~W}$ ICP source power, $-300 \mathrm{~V}$ dc-bias, and $2 \mathrm{mTorr}$ pressure. The reverse leakage remained essentially constant up to anneal temperatures of $500^{\circ} \mathrm{C}$ but increased by more than an order of magnitude at $600^{\circ} \mathrm{C}$ anneals (see Figure 8 ). (The reverse leakage data for $600^{\circ} \mathrm{C}$ anneals was taken at $\sim-15 \mathrm{~V}$ instead of $-30 \mathrm{~V}$ since breakdown occurred at $-30 \mathrm{~V}$ ). A similar trend, with more scatter in the data, was observed under the following ICP conditions: $32 \mathrm{sccm} \mathrm{Cl}{ }_{2}, 8 \mathrm{sccm} \mathrm{BCl}, 5 \mathrm{sccm} \mathrm{Ar}, 750 \mathrm{~W}$ ICP source power, $-100 \mathrm{~V}$ dc-bias, and $2 \mathrm{mTorr}$ pressure. Cao et al. have reported improved breakdown voltages for dry etched n- and p-GaN Schottky diodes annealed in the range of 400 to $700^{\circ} \mathrm{C}$, however anneal temperatures $>800^{\circ} \mathrm{C}$ were needed to produce near-complete recovery in breakdown voltage. ${ }^{(32.33)}$ Unfortunately, higher anneal temperatures were not possible in this study.

\section{CONCLUSIONS}

In summary there are high-density plasma etching conditions for GaN where there is minimal degradation in the reverse leakage current of $\mathrm{p}-\mathrm{i}-\mathrm{n}$ mesa diodes. Both ion energy and plasma flux are important in determining the magnitude of this current, and a high etch rate is not necessarily the best choice for minimizing dry etch damage. Minimum sidewall damage was obtained under low ion energy (dc-bias $<-250 \mathrm{~V}$ ), pressure $\geq 2$ mTorr, and moderate plasma flux conditions. Reverse leakage currents appeared to be somewhat dependent on sidewall etch morphology with the most damage under conditions where the mask-edge degraded and vertical 
striations were observed in the sidewall. Reverse leakage currents did not improve with anneals up to $500^{\circ} \mathrm{C}$ and showed degradation at $600^{\circ} \mathrm{C}$.

\section{ACKNOWLEDGMENTS}

Sandia is a multiprogram laboratory operated by Sandia Corporation, a Lockheed-Martin Company, for the US Department of Energy under contract no. DEAC04-94-AL85000. The work at UF is partially supported by a DARPA/EPRI grant, no. MDA 971-98-1-0006 (D. Radack/J. Melcher) monitored by ONR, and a NSF grant DMR 97-32864 (L.D. Hess). 


\section{REFERENCES}

1. S. Nakamura, IEEE J. Selected Topics in Quantum Electronics 4, 483 (1998).

2. S. Nakamura and G. Fasol, The Blue Laser Diode (Springer, Berlin 1997).

3. F. Ren, C. R. Abernathy, J. M. Van Hove, P. P. Chow, R. Hickman, K. B. Jung, H. Cho, J. LaRoche, R. J. Shul, J. Han, and S. J. Pearton, MRS Internet J. Nitride Semicond. Res. $\underline{3}, 41(1998)$.

4. L. S. McCarthy, P. Kozodoy, S. P. Den Baars, M. Rodwell, and U. K. Mishra, $25^{\text {th }}$ Int. Symp. Comp. Semicond., Nara, Japan, October 1998.

5. J. Han, A. G. Baca, R. J. Shul, C. G. Willison, L. Zhang, F. Ren, A. P. Zhang, G. T. Dang, S. M. Donovan, X. A. Cao, H. Cho, K. B. Jung, C. R. Abernathy, S. J. Pearton, and R. G. Wilson, Appl. Phys. Lett. $\underline{74}$ (1999).

6. W. Yang, T. Nohava, S. Krishnankutty, R. Touearo, S. McPherson, and H. Marsh, Appl. Phys. Lett. $\underline{73}, 1086$ (1998).

7. J. M. Van Hove, R. Hickman, J. J. Klaassen, P. P. Chow, and P. D. Ruden, Appl. Phys. Lett. $\underline{\text { 70, }} 2282$ (1997).

8. A. Osinsky, S. Gangopadhyay, R. Gaska, B. Williams, M. A. Khan, D. Kuksenkov, and H. Temkin, Appl. Phys. Lett. $\underline{71}, 2334$ (1997).

9. L. Zhang, L. F. Lester, A. G. Baca, R. J. Shul, P. C. Chang, C. G. Willison, U. K. Mishra, S. P. Denbaars, and J. C. Zolper, IEEE Transaction Electron Devices, in press.

10. H. P. Gillis, D. A. Choutov, K. P. Martin, M. D. Bremser, and R. F. Davis, J. Electron. Mater. 26, 301 (1997).

11. H.P. Gillis, D. A. Choutov, and K.P. Martin, JOM $\underline{48}, 50$ (1996).

12. H.P. Gillis, D. A. Choutov, K.P. Martin, and Li Song, Appl. Phys. Lett. 68, 2255 (1996). 
13. see for example, R. J. Shul in GaN and Related Materials, ed. S. J. Pearton (Gordon and Breach, NY 1997).

14. R. J. Shul, G. B. McClellan, S. A. Casalnuovo, D. J. Rieger, S.J. Pearton, C. Constantine, C. Barratt, R. F. Karlicek, C. Tran, and M. Schurmann, Appl. Phys. Lett. $\underline{69}, 1119$ (1996).

15. S. A. Smith, C. A. Woldren, M. D. Bremser, A. D. Hansen, and R. F. Davis, Appl. Phys. Lett. $\underline{71}, 3631$ (1997).

16. A. T. Ping, I. Adesida, M. A. Khan, and J. N. Kuznia, Electron. Lett. $\underline{30}, 1895$ (1994).

17. M. E. Lin, Z. F. Fan, Z. Ma, L. H. Allen, and H. Morkoc, Appl. Phys. Lett. $\underline{64}, 887$ (1994).

18. S. J. Pearton, Appl. Surf. Sci. $\underline{117 / 118}, 597$ (1997).

19. S. J. Pearton and R. J. Shul, in Defects in Optoelectronic Materials. ed. S. W. Pang and O. Wada (Gordon and Breach, The Netherlands, in press).

20. S. W. Pang, J. Electrochem. Soc. $\underline{133}, 784$ (1986).

21. A. T. Ping, Q. Chen, J. W. Yang, M. A. Khan, and I. Adesida, J. Electron. Mater. 27, 261 (1998).

22. C. R. Eddy, Jr. and B. Molnar, J. Electron. Mater. $\underline{28,} 314$ (1999).

23. J. Y. Chen, C. J. Pan, and G. C. Chi, Solid-State Electron. $\underline{43}, 649$ (1999).

24. A. T. Ping, A. C. Schmitz, I. Adesida, M. A. Kahn, Q. Chen, and J. W. Yang, J. Electron. Mater. 26, 266 (1997).

25. P. E. Dodd, T. B. Stellwag, M. R. Melloch and M. S. Lundstrom, IEEE Trans Electr. Dev. $\underline{38}$ 1253-1261 (1991).

26. R. J. Shul, M. L. Lovejoy, D. L. Hetherington, D. J. Rieger, G. A. Vawter, J. F. Klem, and M. R. Melloch, J. Vac. Sci. Technol. B13, 27 (1995). 
27. J. Etrillard, F. Heliot, P. Ossart, M. Juhel, and G. Patriarche, J. Vac. Sci. Technol. A14, 1056 (1996).

28. J. Etrillard, P. Ossart, G. Patriarche, M. Juhel, J. F. Bresse, and C. Daguet, J. Vac. Sci. Technol. A15, 626 (1997).

29. J. Han, M. H. Crawford, R. J. Shul, J. J. Figiel, M. Banas, L. Zhang, Y. K. Song, H. Zhou, and A. V. Nurmikko, Appl. Phys. Lett. 73 , 1688 (1998).

30. S. O. Kasap, Principles of Electrical Engineering Materials and Devices, (McGraw-Hill, Chicago, 1997).

31. R. J. Shul, C. I. H. Ashby, C. G. Willison, L. Zhang, J. Han, M. M. Bridges, S. J. Pearton, J. W. Lee, and L. F. Lester, Mats. Res. Soc. Symp. Proc. $\underline{512, ~} 487$ (1998).

32. X. Cao, H. Cho, S. J. Pearton, G. Dang, A. Zhang, F. Ren, R. J. Shul, L. Zhang. R. Hickman, and J. M. Van Hove, Appl. Lett. 75, 232 (1999).

33. X. Cao, S. J. Pearton, A. Zhang, G. Dang, F. Ren, R. J. Shul, L. Zhang. R. Hickman, and J. M. Van Hove, Appl. Lett., in press. 


\section{Figure Captions}

Figure 1. Schematic of $\mathrm{GaN}$ p-i-n junction formed by dry etching.

Figure 2. Reverse leakage current measured at $-30 \mathrm{~V}$ for $\mathrm{GaN} \mathrm{p}-\mathrm{i}-\mathrm{n}$ junctions etched in ICP $32 \mathrm{Cl}_{2} / 8 \mathrm{BCl}_{3} / 5 \mathrm{Ar}$ discharges (500 W source power, $2 \mathrm{~m}$ Torr), as a function of dc-bias.

Figure 3. SEM micrographs for $\mathrm{GaN}$ etched at a) -50 , b) -150 , and c) $-300 \mathrm{~V}$ dc-bias. ICP etch conditions were $32 \mathrm{sccm} \mathrm{Cl}_{2}, 8 \mathrm{sccm} \mathrm{BCl}_{3}, 5 \mathrm{sccm} \mathrm{Ar}, 500 \mathrm{~W}$ ICP source power, and $2 \mathrm{mTorr}$ pressure.

Figure 4. Reverse leakage current measured at $-30 \mathrm{~V}$ for $\mathrm{GaN}$ p-i-n junctions etched in ICP $32 \mathrm{Cl}_{2} / 8 \mathrm{BCl}_{3} / 5 \mathrm{Ar}$ discharges (-100 V dc-bias, $2 \mathrm{mTorr}$ ), as a function of source power.

Figure 5. SEM micrographs for GaN etched at a) 250 , b) 500 , and c) $1000 \mathrm{~W}$ ICP source power. ICP etch conditions were $32 \mathrm{sccm} \mathrm{Cl}_{2}, 8 \mathrm{sccm} . \mathrm{BCl}_{3}, 5 \mathrm{sccm} \mathrm{Ar},-100 \mathrm{~V}$ dc-bias, and 2 mTorr pressure.

Figure 6. Reverse leakage current measured at $-30 \mathrm{~V}$ for $\mathrm{GaN}$ p-i-n junctions etched as a function of $\% \mathrm{Cl}_{2}$ in an $\mathrm{ICP} \mathrm{Cl}_{2} / \mathrm{BCl}_{3} / \mathrm{Ar}$ plasma. Plasma conditions were $-100 \mathrm{~V}$ dc-bias, 2 mTorr, $500 \mathrm{~W}$ ICP power, and $40 \mathrm{sccm}$ total gas flow.

Figure 7. Reverse leakage current measured at $-30 \mathrm{~V}$ for $\mathrm{GaN}$ p-i-n junctions etched in ICP $32 \mathrm{Cl}_{2} / 8 \mathrm{BCl}_{3} / 5 \mathrm{Ar}$ discharges (-100 V dc-bias, $500 \mathrm{~W} \mathrm{ICP}$ source power), as a function of chamber pressure.

Figure 8. Reverse leakage current measured at $-30 \mathrm{~V}$ for $\mathrm{GaN}$ p-i-n junctions etched in ICP $32 \mathrm{Cl}_{2} / 8 \mathrm{BCl}_{3} / 5 \mathrm{Ar}$ discharges (-300 V dc-bias, $500 \mathrm{~W}$ ICP source power, 2 mTorr) as a function of anneal temperature. 


\section{范}

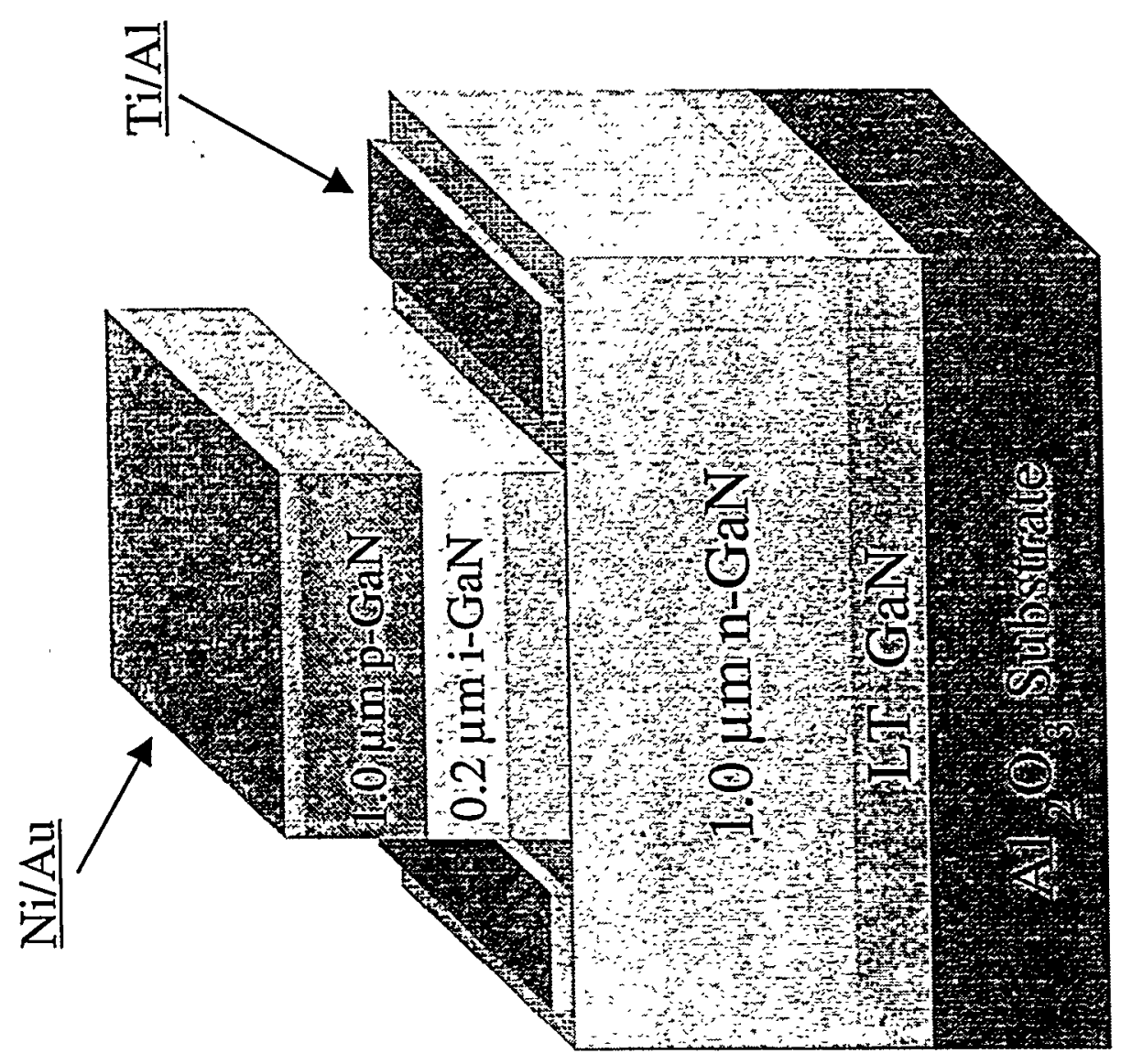




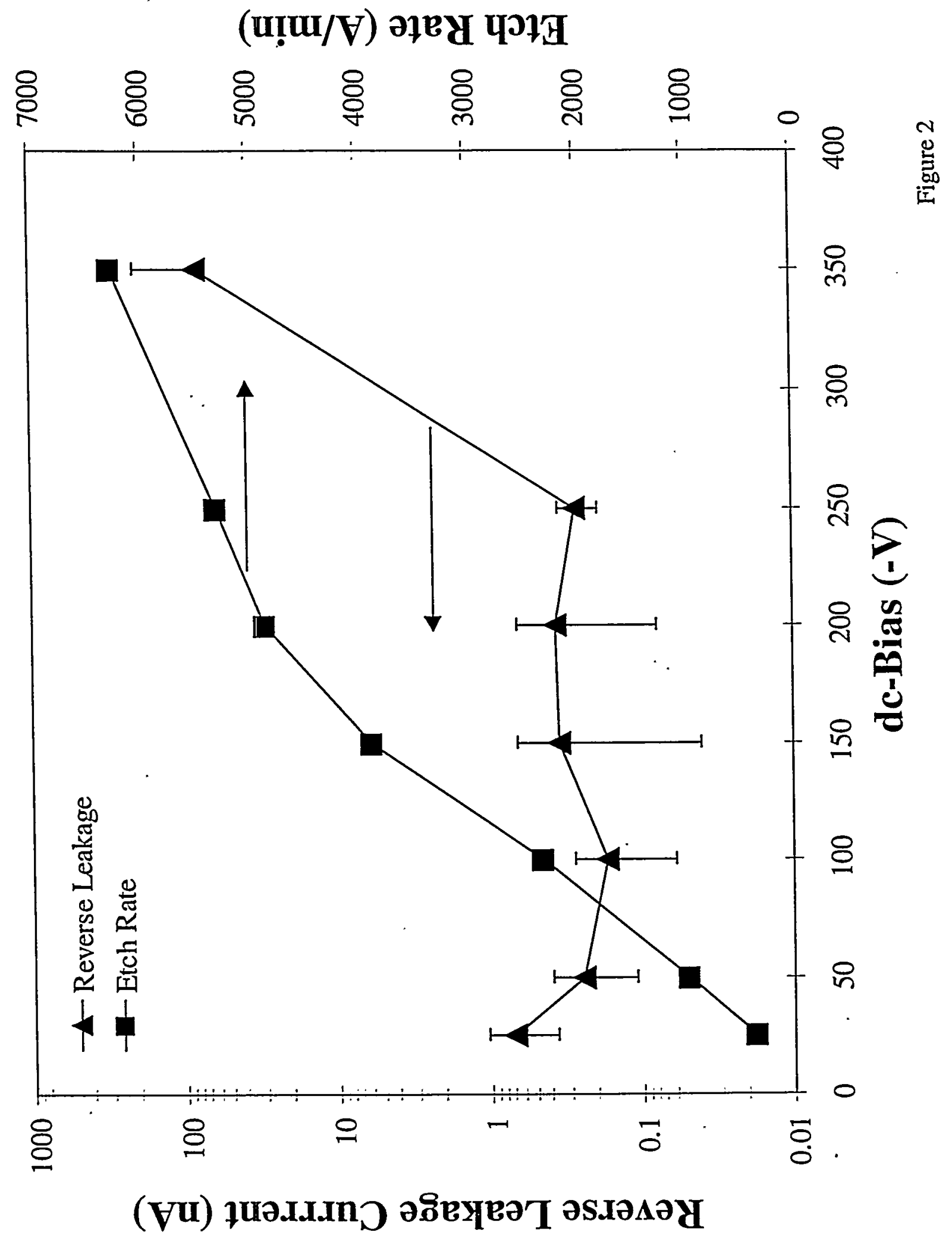



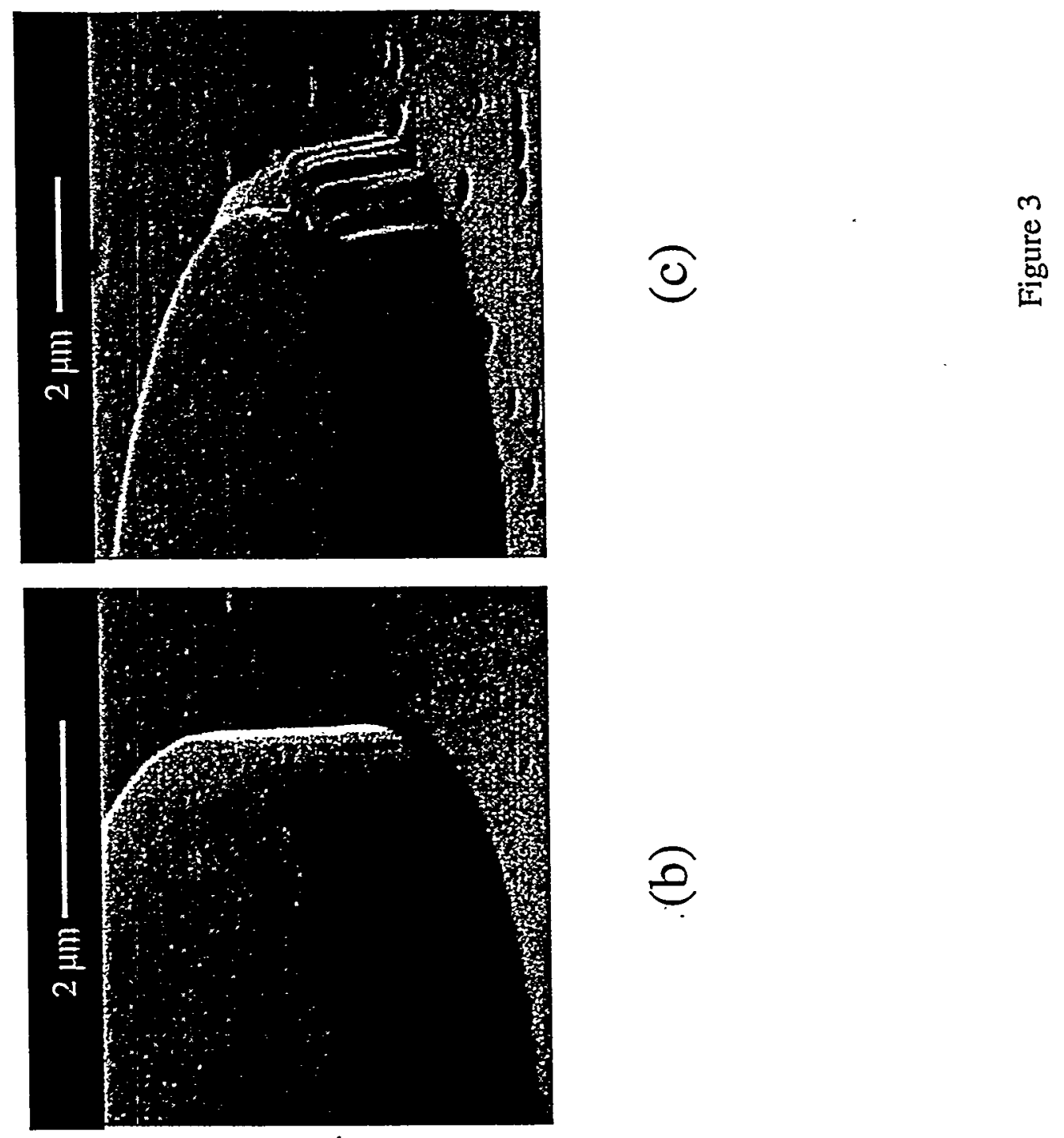

e

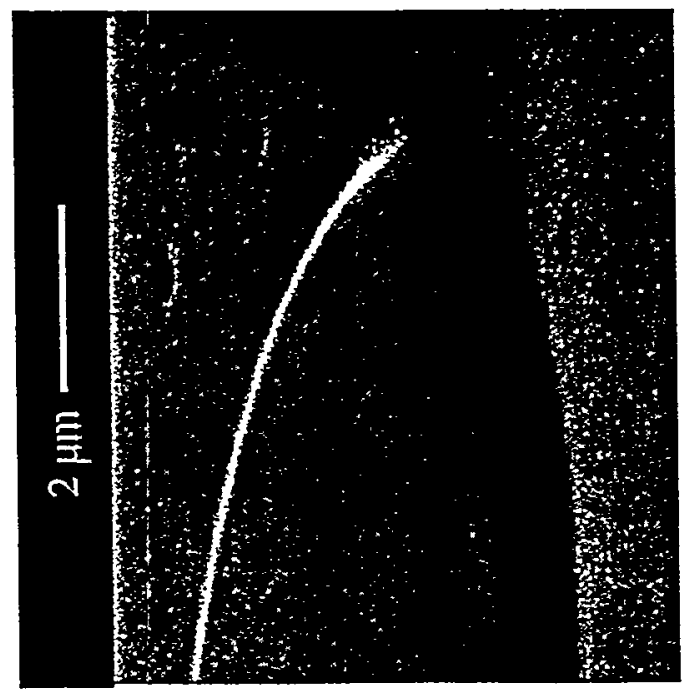

ङ 


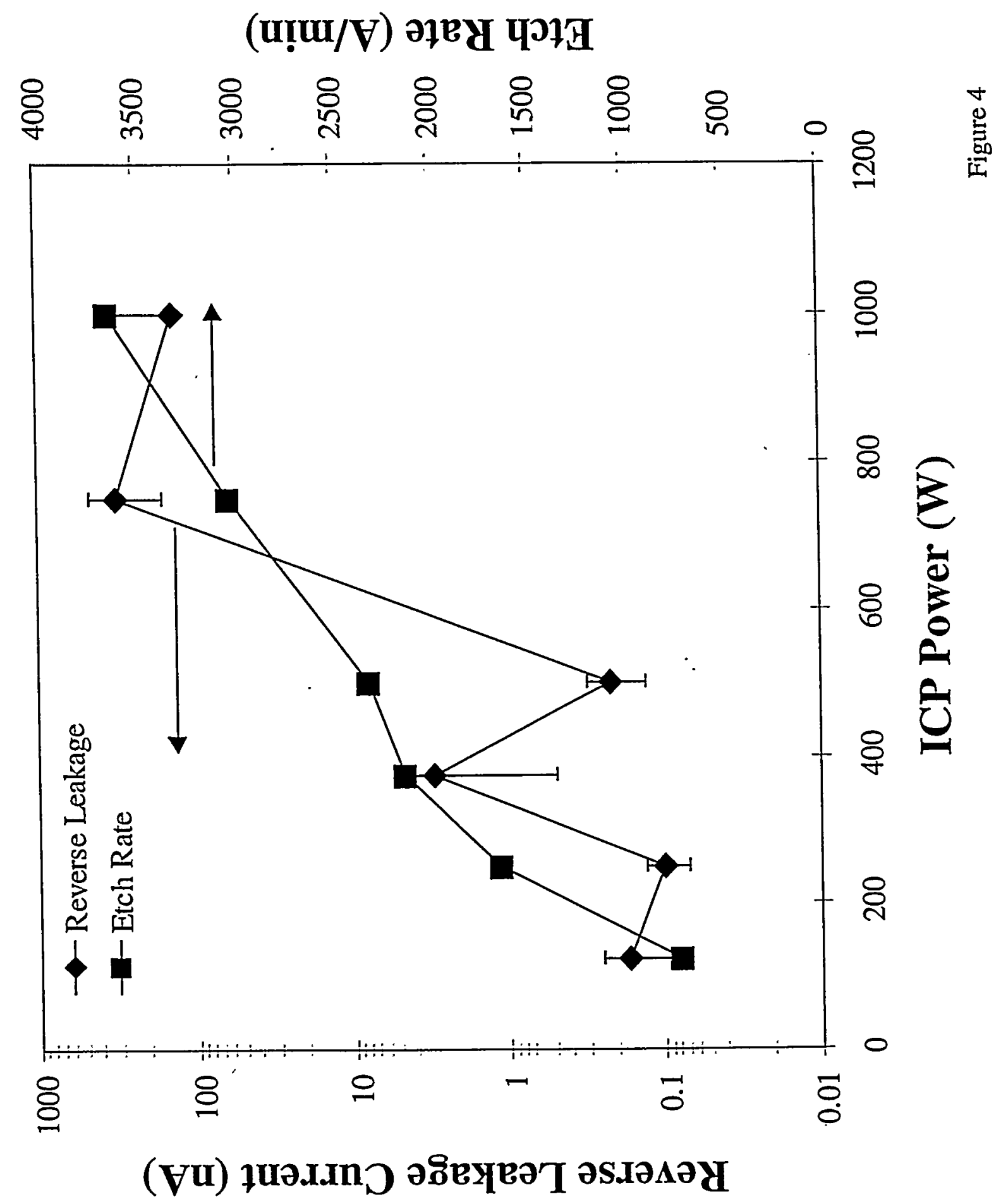




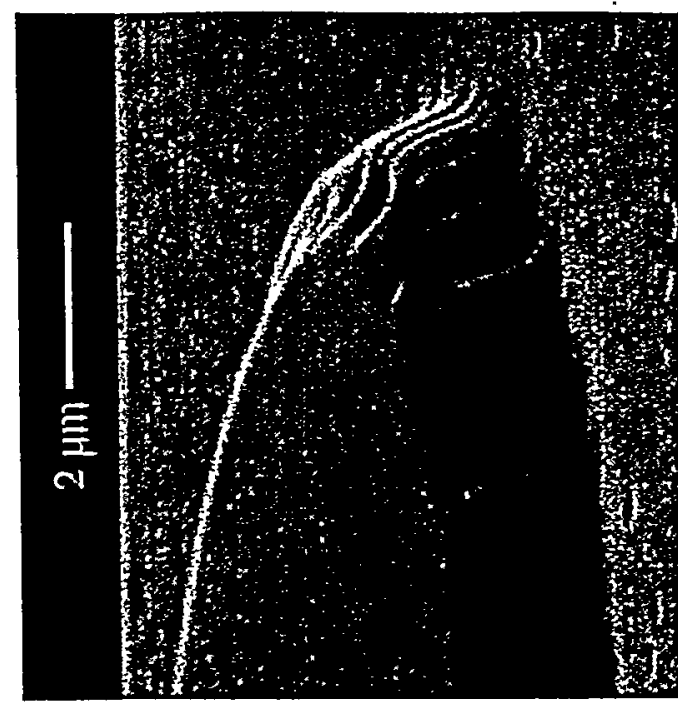

(2)

辛

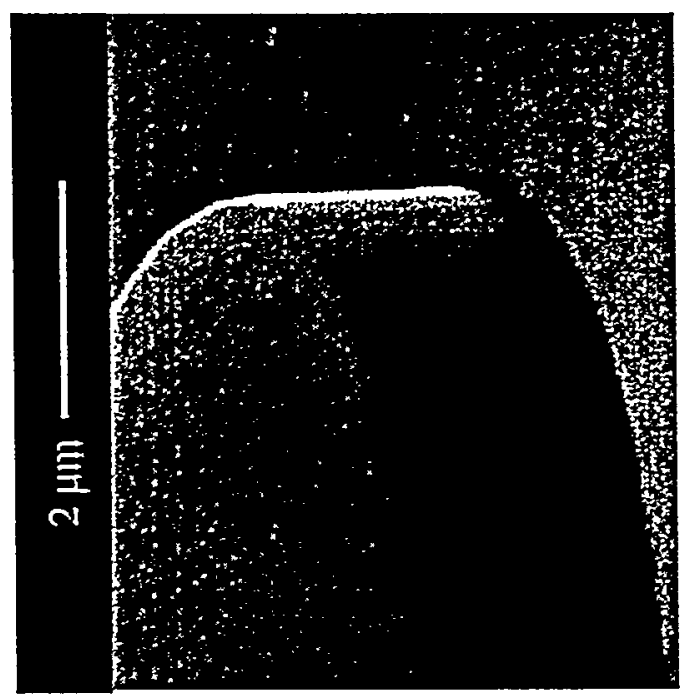

a

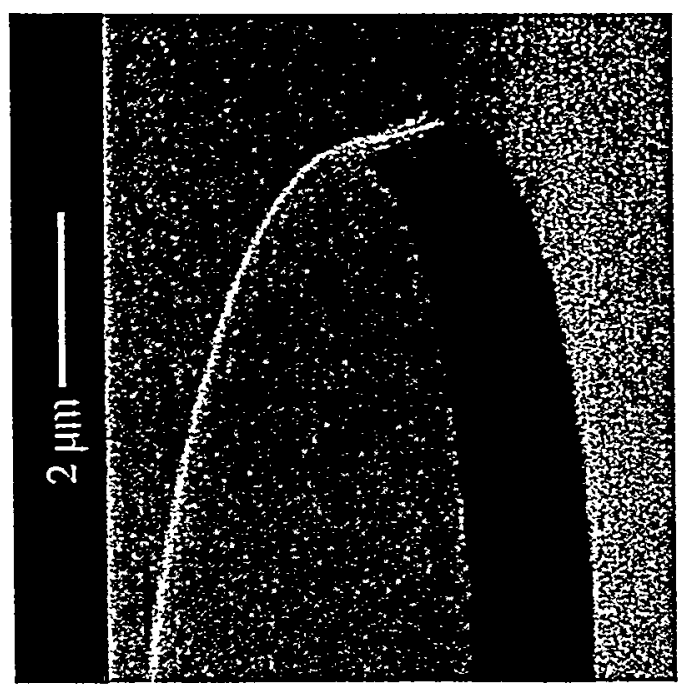

(] 


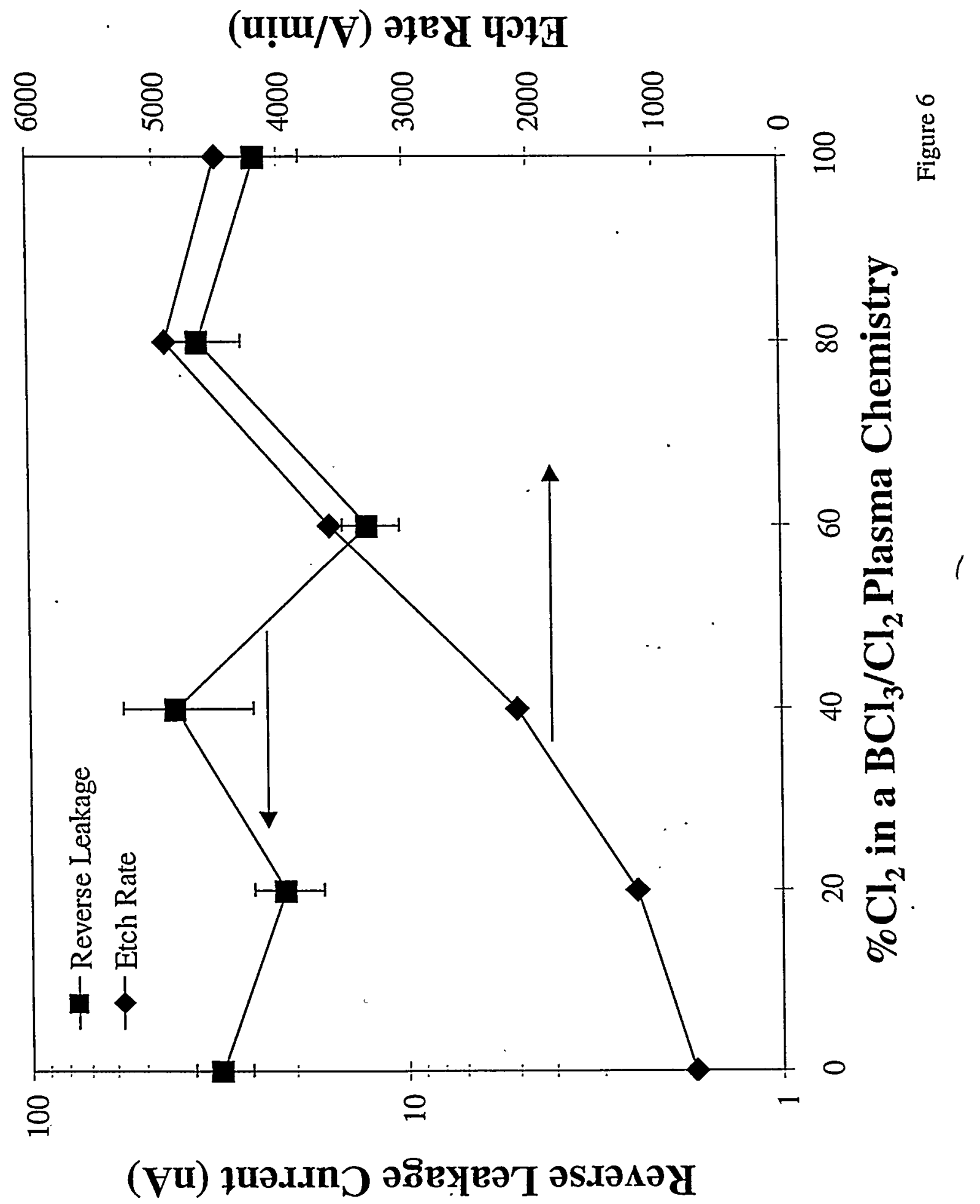




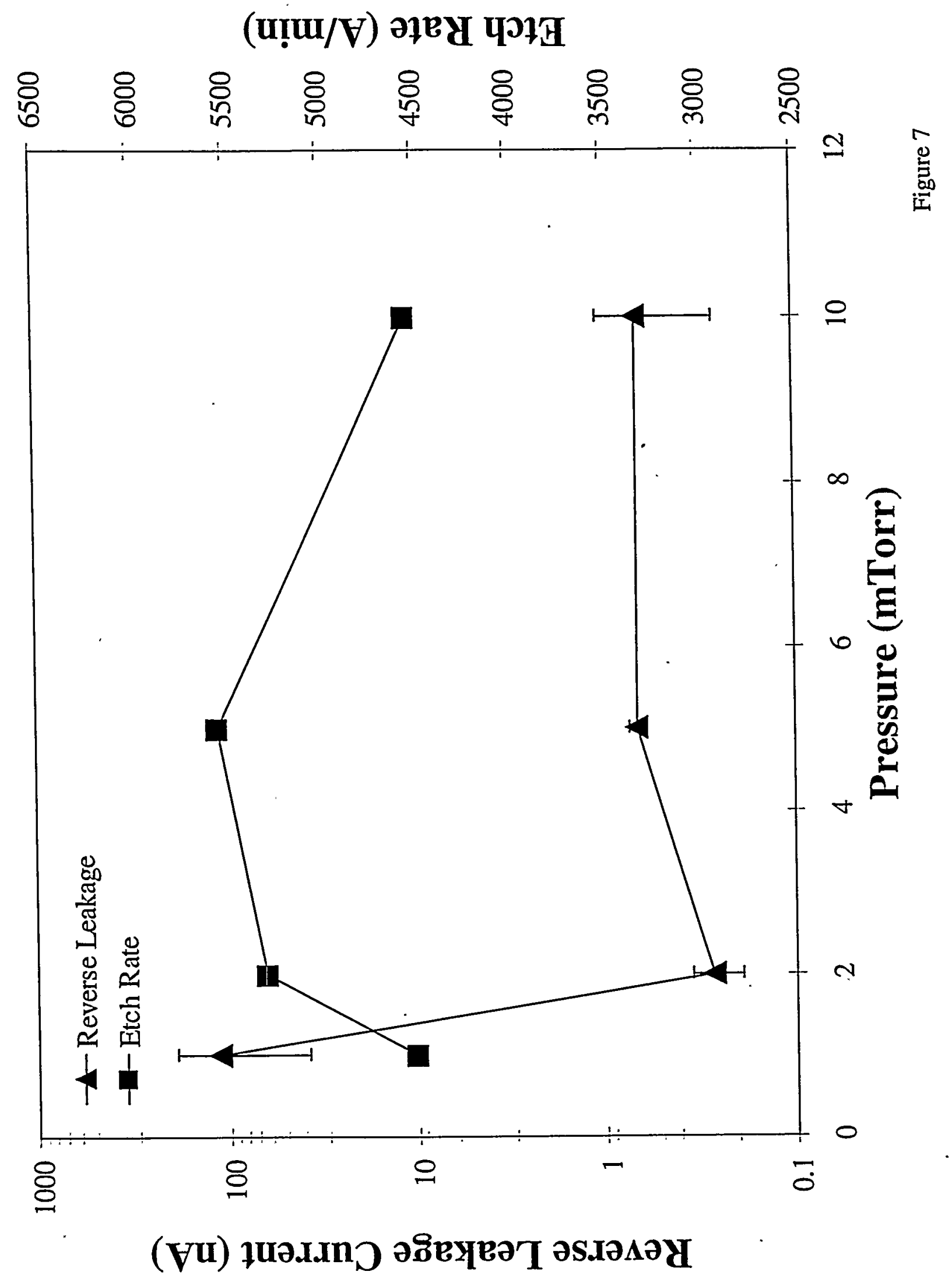




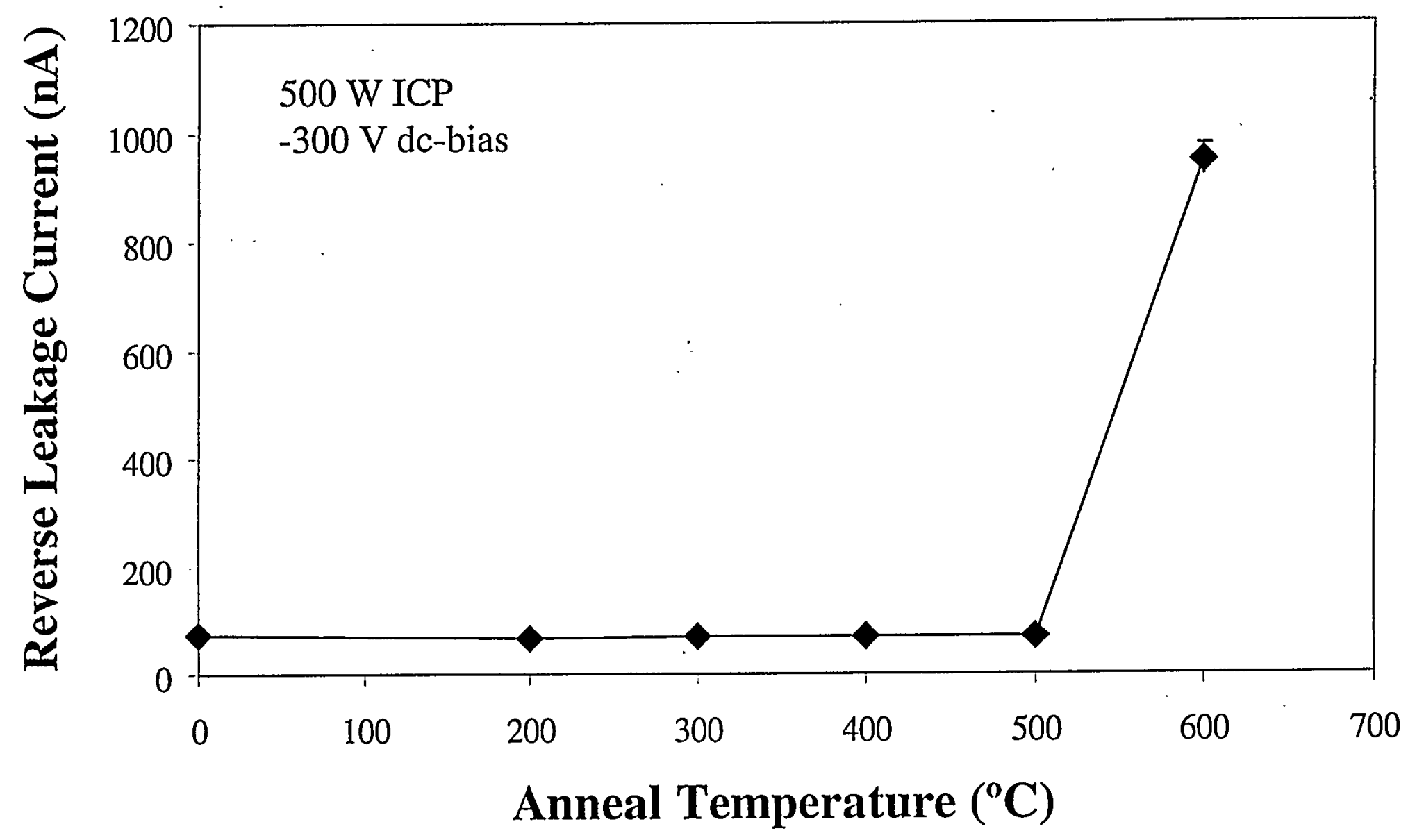

Figure 8 